\title{
Perfil dos Frequentadores de Atividades Culturais: O Caso nas Metrópoles Brasileiras
}

\author{
Bárbara Freitas Paglioto \\ Mestranda - Cedeplar (UFMG) \\ Endereço para contato: Av. Antonio Carlos, 6627 - Prédio FACE, Sala 3040 - Belo Horizonte - MG \\ CEP: 31270-901 -E-mail: paglioto@cedeplar.ufmg.br
}

\author{
Ana Flávia Machado \\ Professora - Cedeplar (UFMG) \\ Endereço para contato: Av. Antonio Carlos, 6627 - Prédio FACE, Sala 3040 - Belo Horizonte - MG \\ CEP: 31270-901 - E-mail:afmachad@cedeplar.ufmg.br
}

Recebido em 07 de março de 2012. Aceito em 03 de julho de 2012.

\section{Resumo}

Este artigo investiga os fatores associados à frequência de indivíduos em eventos culturais com desembolso direto, ou seja, pagamento de ingressos de sessões de cinema, peças de teatro, concertos musicais, shows e exposições artísticas. Por meio de um modelo Probit estima-se, para os anos de 2002-2003 e 2008-2009, a probabilidade de ocorrência desse gasto, considerando-se o perfil socioeconômico do consumidor, efeito do tempo livre (ausência de filhos menores no domicílio) e o efeito de um possível "vício positivo", como proposto por Stigler e Becker (1977) que, neste estudo, é tratado pelo uso de uma variável indicadora de gasto com educação artística e instrumentos musicais, sugerindo complementaridade entre consumo passado e presente.

A fonte de dados é a Pesquisa de Orçamentos Familiares (POF), organizada pelo IBGE. Os resultados mostram que renda e escolaridade são os principais fatores associados ao perfil do consumidor de cultura fora do domicílio, mas evidenciam, também, que gastos com educação artística contribuem positivamente para frequência a eventos culturais.

\section{Palavras-Chave}

cultura, consumo, vício positivo, probit, Brasil

\begin{abstract}
This paper investigates the determinants of attendance to cultural activities in Brazilian metropolitan areas, through expenditures in tickets movies, museums, plays and operas, concerts and art exhibitions. Using a probit model, we estimate the probability of expenditure, considering socio-economic profile, free time effect labsence of children in the household) and positive addiction effect, as suggested by Stigler and Becker (1977). The results show that income and education level of the consumer are the main determinants of attending cultural activities, besides art education, our proxy to positive addiction.
\end{abstract}




\section{Keywords}

culture, consumption, positive addiction, Brazil

\section{JEL Classification}

Z11, D12

\section{Introdução}

Nas sociedades modernas, como salienta Tolila (2007), em virtude do avanço da tecnologia e do ritmo de vida estabelecido, o acesso à cultura passou a ser feito não somente pelo contato direto com a criação artística, mas também e, principalmente, por meio dos produtos culturais. Exemplo desta manifestação é o comportamento da juventude atual, por meio da "cultura de quarto", baseada no uso da Internet, e o surgimento da "cultura de apartamento", associada ao predomínio do consumo de DVD's e CD's.

Tal hábito de consumo desperta interesse na relação entre as práticas domiciliares e as práticas culturais fora do domicílio (aqui também denominadas externas). Consumir cultura fora do domicílio proporciona socialização diferenciada em relação às demais práticas de convívio, como a do ambiente de trabalho, pois os indivíduos se encontram mais relaxados em momentos de lazer. Ademais, o acesso à cultura fora do domicílio implica a não apropriação da produção em forma material e a incorporação de outros custos, como de transporte, alimentação, além do custo de oportunidade.

Identificar os fatores associados ao consumo de bens e serviços culturais significa compreender as restrições de acesso, individuais e sociais. Os achados auxiliam na formulação de políticas públicas e no planejamento privado do setor cultural. Neste artigo, analisam-se os fatores associados à frequência a eventos culturais que implicam dispêndio direto, tais como sessões de cinema, peças de teatro, concertos musicais, shows, exposições artísticas, identificando quem é o usuário referência.

Além do perfil socioeconômico do consumidor de cultura fora do domicílio e o efeito de tempo livre (ausência de filhos menores no domicílio) para tal prática, busca-se investigar a condição de "vício positivo", como pressuposto por Stigler e Becker (1977), por meio 
de uma proxy que mede a incidência de gasto com educação artística e instrumentos musicais, indicando complementaridade entre consumo passado e presente. Os resultados são apresentados para o Brasil Metropolitano, recorrendo aos dados da Pesquisa de Orçamentos Familiares (POF), realizada entre os períodos 20022003 e 2008-2009.

Este artigo está organizado em cinco seções, incluindo a introdução. $\mathrm{Na}$ segunda seção, apresenta-se uma breve revisão do modelo de Stigler e Becker (1977) e dos achados sobre o comportamento do consumidor de cultura em outros países e no Brasil, segundo a literatura especializada. A seguir, a terceira seção esclarece as questões metodológicas concernentes à fonte de dados, variáveis utilizadas e estratégia econométrica. Os resultados são discutidos na quarta seção e, por fim, na última seção, são tecidas considerações a respeito dos principais resultados e implicações.

\section{Demanda por Bens e Serviços Culturais: Revisão Teórica e Empírica}

Um dos princípios da Agenda 21 da Cultura ${ }^{1}$ é o de que

"o acesso ao universo cultural e simbólico em todos os momentos da vida, desde a infância à velhice, constitui um elemento fundamental de formação da sensibilidade, da expressividade, da convivência e da construção de cidadania (...)" (Agenda 21..., 2004, p.3)

O consumo de bens e serviços artístico-culturais pode ser considerado, portanto, um tipo de consumo desejável e de grande importância para o desenvolvimento socioeconômico, à medida que amplia as capacidades criativas e expressivas do indivíduo e estimula a coesão social, sendo uma das formas pela qual a cidadania se expressa. $\mathrm{Na}$ prática, porém, este tipo de consumo está longe de ser universal, o que implica a importância do desenvolvimento de ferramentas para

\footnotetext{
1 A Agenda 21 da Cultura é um documento que expressa o compromisso das cidades e governos locais do mundo todo, que a aprovaram, com o desenvolvimento cultural. Foi aprovada em maio de 2004, pelo IV Fórum das Autoridades Locais pela Inclusão social de Porto Alegre, no Primeiro Fórum Universal das Culturas, em Barcelona.
} 
compreender quais os fatores associados à demanda por produtos desta natureza. O modelo de demanda, como o modelo de preferências estáveis, desenvolvido por Stigler e Becker (1977), é considerado referência para tratamento do consumo de bens e serviços culturais. Assumindo a hipótese de endogeneidade dos gostos e preferências, definem a formação de capital humano e o "vício positivo."

No modelo proposto, as famílias maximizam utilidade de acordo com sua função de produção, que tem como insumos não só bens adquiridos no mercado, como também seu capital humano e a jornada diária. Para os itens que não são adquiridos no mercado, como estoque de capital humano e bens produzidos no domicílio, os preços são definidos pelo custo de oportunidade do tempo de produção, o preço-sombra. Assim, é possível estabelecer como esses preços se diferenciam entre pessoas e períodos. O capital humano seria uma soma do capital pessoal e social. Enquanto o capital pessoal diz respeito ao consumo e as experiências sociais passadas (escolarização, educação artística) que influenciam a utilidade presente e futura do indivíduo, o capital social se refere à influência dos pares e demais componentes de sua rede social.

Uma hipótese básica é a de que um crescimento do capital humano influencia positivamente o consumo de cultura através de um processo de depuração do gosto, que não estaria relacionado a uma mudança nas preferências, como sugerido por Marshall, uma vez que a função utilidade é considerada estável, mas a uma redução do preço-sombra, custo de oportunidade relacionado ao consumo de cultura. Pode-se chamar de "ganho de introspecção" uma melhor assimilação com o passar do tempo, que torna o custo de oportunidade cada vez menor, o que amplia o consumo. Sendo assim, a utilidade marginal neste caso é crescente, gerando o efeito de vício.

A ideia de que a exposição às artes é necessária para que o indivíduo amplie a sua capacidade de compreensão e apreciação também é defendida de um ponto de vista sociológico por autores como Bourdieu (Diniz, 2009). Bourdieu ([1979] 2007) elabora o conceito de capital cultural, referindo-se ao bom gosto, às maneiras apropriadas, à sofisticação cognitiva e ao conhecimento ou à receptividade a produtos

2 A ideia de vício positivo remete a Marshall, porém, este relaciona o vício positivo a uma mudança nas preferências. "Quanto mais boa música uma pessoa ouvir, mais provável é que seu gosto por ela aumentará. (...) Quanto mais produtos e serviços culturais uma pessoa consumir, mais gosto terá por esse consumo." (Marshall apud Reis, 2007, p.18) 
culturais considerados legítimos (como música clássica, teatro e literatura), como um conjunto de qualificações produzido pela família e pelo sistema escolar.

Entretanto, as mudanças tecnológicas e as políticas públicas têm ampliado a capacidade de acesso à cultura. DiMaggio (1987) pontua que, no atual contexto relacionado ao consumo de massa e redução das barreiras entre os gêneros artísticos e o público, os padrões de demanda tendem a ser mais ecléticos e dissonantes. Herscovici (1995) evidencia que o acesso à cultura, por intermédio das mídias sociais virtuais, ou, mais propriamente, a cultura digital, tem se tornado um veículo para a formação cultural de uma sociedade.

Neste mesmo contexto, Peterson \& Simkus (1992), ao tratar do gosto por música, ressaltam que emerge no mundo contemporâneo uma categoria de consumidores a que denominam "omnívoros", por apreciarem produtos diversificados, elitizados e não elitizados. Este tipo de consumidor, segundo os autores, pode ser encontrado em todas as classes sociais, assim como os indivíduos "unívoros", engajados em poucas atividades culturais e gostos limitados a gêneros restritos apesar de estes serem associados, frequentemente, às classes menos favorecidas.

Ademais, para Trienekens (2002), ao se expandir a definição de arte, incluindo a cultura popular, baseada em hábitos e símbolos de uma comunidade, outros determinantes do consumo devem ser tratados. $\mathrm{Na}$ cultura popular, por exemplo, o efeito da raça/etnia pode ser similar em magnitude ao efeito dos indicadores de classe (educação e renda). Assim, a literatura sobre demanda por esses bens destaca a importância de se levar em consideração as características de distinção social, como renda e escolaridade, e ainda a influência dos pares e o contato precoce com a arte na definição do perfil de consumidores de produtos culturais, tanto de massa quanto os elitizados.

Ao se tratar especificamente do consumo fora do domicílio, é preciso destacar a relevância do custo de oportunidade relacionado ao tempo despendido para o consumo. Becker (1965) aponta que assistir a uma peça de teatro, por exemplo, inclui custos que superam o preço do ingresso. Tal atividade requer tempo para deslocamento e, sobretudo, para a assistência. Deste modo, há uma alocação de tempo que poderia ser utilizada em outra atividade, como a de trabalho para o 
mercado ou destinado a tarefas domésticas, configurando em custo de oportunidade, medido pelo valor da renda por hora do espectador. Este custo de oportunidade tende a ser mais elevado para as famílias de renda mais alta, uma vez que a taxa de salário é mais elevada. Tolila (2007) acredita que, nos últimos anos, especialmente para executivos e profissionais qualificados, o efeito do custo de oportunidade está mais do que compensando o efeito da restrição orçamentária. Para ele, a propagação de festivais culturais é uma resposta a essa tendência de se consumir o máximo possível em um menor espaço de tempo.

$\mathrm{Na}$ literatura internacional, a grande maioria dos trabalhos de investigação da demanda por bens e serviços culturais trata de um determinado mercado especificamente. Tal enfoque é factível, porque, tanto em países europeus quanto nos Estados Unidos, há bases de dados organizadas em séries temporais mais longas e detalhadas sobre diversos setores culturais. Muitos desses trabalhos se referem aos espetáculos ao vivo ou especificamente a teatro.

São vários os exemplos datados desde a década de 1960. Moore (1966) investiga porque a demanda por espetáculos da Broadway cresceu tão lentamente no período 1928-1963. Gapinski (1984) analisa o comportamento da produção e da demanda da companhia de teatro britânica Royal Shakespeare Company (RSC). A base de dados é referente ao período de 1968-1978 e está dividida entre as duas sedes da companhia, Aldwych e Stratford. O mesmo autor (Gapinski,1986) estuda o efeito de uma determinada categoria de apresentações ao vivo como substituto de outros tipos de apresentações ao vivo, ${ }^{3}$ dado que este é um grupo bastante heterogêneo.

Recentemente, pode-se citar Werck e Heyndels (2007), que tratam da frequência ao teatro belga e sua forte tendência à queda a partir dos anos 1980. A sua amostra é composta por 59 companhias de teatro no período entre 1980-2000. Ateca-Amestoy (2008) investiga a demanda por peças de teatro nos Estados Unidos. A amostra contém 17.135 questionários aplicados em 2002. E, finalmente, Zieba (2009) investiga a elasticidade-renda e a elasticidade-preço da demanda por teatro na Alemanha, partindo de uma amostra de 174 teatros alemães, durante 40 anos (1965-2004).

3 Por exemplo, o efeito de espetáculos de dança como substitutos de peças teatrais ou de óperas e vice-versa. 
Em menor número estão os trabalhos que consideram setores da indústria cultural, como os setores de livros, discos e cinema. Um exemplo na literatura internacional é Ringstad e Loyland (2006) sobre a demanda por livros na Noruega, que trabalha com uma base de dados contendo o consumo domiciliar de livros num período de duas semanas. Sua amostra contém 18.000 residências, entre os anos de 1986-1999.

De um modo geral, todos esses trabalhos trazem resultados que confirmam a hipótese de que a demanda por bens e serviços artístico-culturais é elástica em relação à renda, caracterizando os bens culturais como bens de luxo. Nos casos em que esse efeito esperado não coincide com os resultados encontrados - Moore (1966), Gapinski (1986) -, os autores levantam o problema do efeito ambíguo da renda sobre a demanda por espetáculos ao vivo, uma vez que, se por um lado o desejo de consumir aumenta quando a renda aumenta, por outro, o custo de oportunidade de ir ao teatro também cresce com o crescimento da renda, dado que as artes performáticas são atividades intensivas em tempo.

Zieba (2009) busca separar esses dois efeitos utilizando o conceito de "renda ampla", considerando a renda total como sendo a soma da renda disponível para consumo mais uma renda resultante do valor do tempo disponível para o lazer. ${ }^{4} \mathrm{O}$ trabalho compara dois modelos de estimação, o primeiro incluindo somente a renda disponível para consumo, no qual encontra uma elasticidade-renda próxima de 1 , e o segundo modelo substituindo a renda disponível para consumo pela "renda ampla" ${ }^{5}$ e acrescentando o preço do lazer como variável explicativa.

O resultado é uma elasticidade-renda muito mais alta no segundo modelo, o que o faz concluir que os espetáculos teatrais somente podem ser considerados bens de luxo quando se considera renda em sentido amplo. O preço do lazer, por sua vez, é significativo e tem efeito negativo, o que explicaria o resultado encontrado quando se considera somente a renda disponível, ou seja, o efeito positivo da renda ampla é, em parte, anulado pelo custo de oportunidade.

\footnotetext{
${ }^{4}$ O preço do lazer seria o custo de oportunidade, calculado a partir da taxa de salário real ajustada pelo nível de desemprego.

5 Renda ampla é quase seis vezes maior que a renda disponível.
} 
Em relação à elasticidade-preço, é consensual a inelasticidade da demanda em relação ao preço do ingresso dos espetáculos ao vivo. Já no caso da demanda por livros (Ringstad e Loyland, 2006), a elasticidade-preço foi considerada alta. Essa diferença de resultado revela o quão heterogêneo é o mercado de bens culturais.

Quando se trata do efeito do preço de bens substitutos, em geral o efeito é positivo, como esperado, embora haja muita diferença na definição de bem substituto. Assumindo atividades de lazer como substitutos a Royal Shakespeare Company, Gapinski (1984) constata que o preço dos substitutos não teria efeito significativo.

O mesmo resultado é encontrado em Werck e Heyndels (2007), que consideram cinema, literatura e outras atividades performáticas como substitutos do teatro. Entretanto, Ateca-Amestoy (2008) encontra um resultado que demonstra que outras formas de contato com o teatro, por meio de literatura, filmes e programas relacionados, são complementares à demanda por espetáculos, e não substitutos. No caso dos livros, em Ringstad e Loyland (2006), a elasticidade-cruzada revela que os demais bens culturais são substitutos.

Tanto Werck e Heyndels (2007), como Zieba (2009), incluem em suas análises variáveis utilizadas como proxies para a qualidade, optando por medidas objetivas tais como tamanho do elenco e proporção de novas produções, no primeiro trabalho, ou gastos com a produção de cenários e figurinos e número de espectadores convidados, no segundo. Todas essas variáveis se mostraram significativas.

Em relação às variáveis sociodemográficas, Ateca-Amestoy (2008) e Ringstad e Loyland (2006) constatam que idade, ser solteiro e ser do sexo feminino aumentam a probabilidade de demandar o bem ou serviço cultural. No caso dos livros, Ringstad e Loyland (2006) percebem ainda um efeito negativo e bastante significativo de se ter filhos com menos de sete anos de idade sobre a demanda por livros. Estes mesmos autores também encontram efeito significativo para variável de localização, quanto maior a cidade maior a demanda, haja vista o papel do efeito escala sobre tal consumo.

Ateca-Amestoy (2008) pertence à linha de discussão que considera a especial significância das variáveis de capital cultural e se baseia no modelo de Stigler e Becker (1977) na explicação da diferença de 
comportamento, encontrando um efeito positivo e significativo para a educação formal e um efeito ainda mais expressivo para a educação e trabalho artísticos. ${ }^{6}$

No caso brasileiro, a principal base de dados utilizada nos trabalhos empíricos é a POF - IBGE (2006), Silva et al. (2007) e Diniz e Machado (2011) utilizam a POF 2002-2003, enquanto Machado, Menezes e Diniz (2010) utilizam também a POF 1996-1997. Estes trabalhos consideram, em sua maioria, esses bens de forma geral e não um específico, como visto na literatura internacional. Exceções são Machado, Menezes e Diniz (2010) e Earp (2009), que abordam especificamente a demanda por cinema.

Diniz e Machado (2011) procuram caracterizar o perfil dos consumidores de bens e serviços artístico-culturais nas principais metrópoles brasileiras. ${ }^{7}$ Consideram que o consumo é determinado por características individuais e do meio e relacionam o consumo com o perfil do domicílio e com a presença de equipamentos culturais. ${ }^{8}$ Os resultados da estimação do modelo econométrico indicam que os principais determinantes de um consumo mais amplo e mais diversificado de bens e serviços culturais seriam a renda e a educação. Em relação ao índice de oferta de equipamentos culturais, este tem efeito negativo no dispêndio domiciliar. Uma possível interpretação seria a maior participação do poder público nos locais de maior oferta, subsidiando atividades culturais através de menores preços ou promoção de eventos gratuitos.

Machado, Menezes e Diniz (2010) investigam especificamente a demanda por cinema nas principais regiões metropolitanas brasileiras, enfatizando a hipótese de vício positivo do modelo proposto por Stigler e Becker (1977). Para tanto, consideram determinantes da demanda por cinema o preço do ingresso, os preços dos bens substitutos (DVD, TV e internet), dummies regionais, além das características individuais idade, sexo, escolaridade, se tem ou não filhos menores de 18 anos e uma variável proxy para consumo passado, criada a partir dos dados com uma defasagem de seis anos. Os resultados identificam o cinema como um bem normal - diferente do que

\footnotetext{
${ }_{7}^{6}$ Considera aulas de teatro e atuação.

7 Belém, Fortaleza, Recife, Salvador, Belo Horizonte, Rio de Janeiro, São Paulo, Curitiba e Porto Alegre. Incluem-se ainda os municípios de Goiânia e o Distrito Federal

8 Como fonte de dados sobre equipamentos culturais utiliza o Suplemento de Cultura da Pesquisa de Informações Básicas Municipais - MUNIC 2006.
} 
se vê na literatura para as artes performáticas, por exemplo, em geral classificadas como bens de luxo - e inelástico em relação ao preço. A variável proxy para consumo passado se mostra significativa e de efeito positivo, comprovando a hipótese de vício positivo.

Earp (2009) investiga a demanda por cinema a partir de dados de pesquisa realizada pelo Instituto Datafolha em 2008, que revela o comportamento do público diante das opções de entretenimento nas dez regiões metropolitanas brasileiras. Sua análise mostra que, para a maioria das pessoas, frequentar salas de cinema costuma ser uma atividade eventual, e tempo e renda seriam as principais restrições à demanda por cinema.

O aumento dos preços dos ingressos se mostrou como um fator importante da redução da demanda, mas, para além disso, o fato de existirem vários outros gastos associados à ida ao cinema, com transporte e atividades de lazer complementares - a ideia de "combo" de entretenimento - parece ser um fator fundamental. Ao mesmo tempo, as vantagens crescentes dos bens substitutos, como aluguel de DVDs e TV a cabo, que não estão associados a tantos gastos complementares, favorecem a redução da demanda por cinema. Earp (2009) destaca também o fato de que jovens cujos pais costumavam levar ao cinema tendem a valorizar mais essa atividade.

Botelho e Fiore (2005) investigam o consumo de lazer e cultura na Região Metropolitana de São Paulo, a partir de uma amostra de 2.002 questionários elaborados pelos próprios autores. As diferentes atividades de lazer e cultura são divididas em práticas externas e domiciliares, ressaltando o predomínio das práticas domiciliares, fenômeno que chamam de "cultura de apartamento" ou "cultura em domicílio". Os dados apontam que quase a totalidade dos frequentadores de práticas culturais externas tem altos índices de consumo de atividades domiciliares, verificando que as diversas práticas se alimentam mutuamente. Das práticas externas, ir ao cinema se revela a mais comum e a que está mais bem distribuída entre as classes de renda.

Assim, o presente trabalho pretende ser mais uma contribuição para o caso brasileiro, enfatizando o perfil do consumidor que adquire bens e serviços culturais fora do domicílio e a relação deste consumo com o consumo dos demais bens e serviços culturais. 


\section{Metodologia}

Baseado na fundamentação teórica de Stigler e Becker (1977), e considerando ainda as demais contribuições da sociologia sobre o consumo de cultura, é possível estabelecer que a demanda por bens e serviços artístico-culturais deve ser considerada função não só de fatores econômicos tais como preço do bem, preço de bens substitutos, bens complementares, qualidade do bem e renda disponível para consumo, como também de fatores sociodemográficos, tais como gênero, idade e raça, fatores educacionais e fatores regionais. Além de estar associada diretamente ao estoque de capital cultural acumulado.

Individualmente, deve-se considerar o papel da educação, seja a educação formal ou a educação artística, e das características demográficas, tais como gênero, idade e raça. Estes fatores estão relacionados ao contexto sociocultural no qual o agente está inserido, que pode fazer com que o acesso à cultura se estabeleça de forma diferenciada para homens e mulheres, brancos e negros, judeus e católicos, etc.

A idade pode ainda estar relacionada a uma redução no custo de oportunidade do consumo, uma vez que, ao longo dos anos, o indivíduo dispóe de mais tempo livre, e o custo de acumular capital cultural (preço do tempo) é menor, dado o estoque que já formou. No caso específico da demanda por produtos culturais fora do domicílio, é possível acrescentar ainda a influência do número de filhos pequenos, que, por necessitarem de maior atenção, reduzem a probabilidade de se possuir tempo disponível para atividades externas.

Devem-se considerar também variáveis geográficas que estão ligadas a questões histórico-culturais e controlam as diferenças entre as condições de oferta como, por exemplo, as vantagens dos grandes centros urbanos.

Um modelo capaz de identificar os principais fatores relacionados à probabilidade de gasto privado com bens e serviços culturais fora do domicílio $\mathrm{P}\left(y_{i}\right)$, pode ser descrito a partir da seguinte função:

$$
P\left(y_{i}\right)=f\left(S e_{i}, S d_{i}, C_{i}, E_{i}, E A_{i}, G_{i}, T\right)
$$


Onde $S e_{i}$ seriam as características socioeconômicas do domicílio; $S d_{i}$ seriam as características sociodemográficas do chefe do domicílio - incluindo o número de filhos com idade inferior a 10 anos; $\mathrm{C}_{i}$ compreende os gastos com bens complementares; $E_{i}$ é o nível de escolaridade do chefe de domicílio; $E A_{i}$ seria uma medida de educação artística do chefe do domicílio; $G_{i}$ são as dummies de regiões metropolitanas e $\mathrm{T}$ uma binária para captar o efeito temporal.

Dentre as características educacionais, destacam-se a educação e prática ${ }^{9}$ artística que, por influenciarem diretamente a formação de capital cultural, está diretamente ligada à formação do hábito ou comportamento de "vício positivo", como considerado por Stigler e Becker (1977).

\section{Base de Dados}

As bases de dados utilizadas são as Pesquisas de Orçamentos Familiares (POFs) de 2002-2003 e 2008-2009, realizadas pelo IBGE. A POF é uma pesquisa amostral e fornece uma ampla base de informações sobre as características dos domicílios, informações socioeconômicas e sociodemográficas de cada membro das famílias entrevistadas, as despesas anuais individuais e coletivas de cada unidade de consumo dentro do domicílio, assim como os rendimentos e, ainda, questões de caráter subjetivo relativas à qualidade de vida das famílias.

O período de realização da POF 2002-2003 vai de julho de 2002 a junho de 2003, enquanto o da POF 2008-2009 vai de maio de 2008 a maio de 2009. Como a coleta de dados da POF tem duração de um ano, e as informações coletadas também são sobre um período de 12 meses, o próprio IBGE equipara as variáveis monetárias, utilizando como data de referência 15 de janeiro de 2003 e 15 de janeiro de 2009, respectivamente.

O plano de amostragem das duas pesquisas é basicamente o mesmo. Em comparação à POF de 2002-2003, a POF de 2008-2009 possui uma diferença na estratificação amostral, mas é possível agregar os estratos da POF mais recente de forma a torná-lo totalmente compatível com a pesquisa anterior. Outra diferença é a não inclusão

\footnotetext{
9 Presença de instrumentos musicais no domicílio.
} 
na última POF da Região Administrativa de Brasília, que, diferente da POF 2002-2003, não foi separada para compor um estrato geográfico.

Para compatibilizar as duas bases, tornando possível compará-las em termos reais, os valores da POF 2002-2003 foram corrigidos pela variação de preços no período entre as datas de referência das pesquisas. Essa correção foi feita com base no Índice de Preços ao Consumidor (IPC) elaborado pela Fundação Getúlio Vargas.

As informações contidas na POF dizem respeito a gastos e, portanto, não permitem mensurar o consumo de bens e serviços artísticos culturais realizados por outros meios que não via dispêndio, o que limita as possibilidades de investigação à demanda por bens privados, não gratuitos.

\section{Estratégia Econométrica}

O principal problema relacionado à investigação do comportamento das famílias com gastos em produtos artístico-culturais está ligado à forte censura dos dados, uma vez que se sabe que somente uma parcela restrita da população realiza esse tipo de consumo. Este problema é ainda mais grave quando se trata especificamente de consumo de cultura fora do domicílio. Buscou-se, então, uma estratégia econométrica que permitisse estabelecer quais as características de distinção deste grupo específico de consumidores do restante da população, que não possui o hábito de consumir produtos culturais fora do domicílio.

Os resultados apresentados, portanto, restringem-se à compreensão dos fatores relacionados à probabilidade de se despender ou não receita com produtos artístico-culturais fora do domicílio, e são estimados por meio de um Probit, baseado principalmente em variáveis sociodemográficas e econômicas, tendo por unidades de análise os domicílios das nove regiões metropolitanas presentes nas POFs 20022003 e 2008-2009. As duas bases utilizadas foram empilhadas e tratadas como uma cross section, incluindo-se uma variável de ano para identificar as diferenças não controladas entre os períodos. 
O modelo Probit é um modelo de resposta binária estimado pelo método de máxima log-verossimilhança com base em um conjunto completo de variáveis explicativas, cujo interesse reside na probabilidade de resposta, assumindo-se que esta probabilidade é linear em um conjunto de parâmetros, de tal forma que a função $f(z)$ assuma valores estritamente entre zero e um para todos os valores de $\mathrm{z}$. (Woldridge, 2007)

A natureza não linear de $f(z)$ dificulta a interpretação da magnitude dos efeitos de cada variável explicativa sobre a probabilidade de sucesso, que não é representado diretamente pelo valor do coeficiente, mas pode ser calculado através das derivadas parciais.

Assim podemos representar genericamente o modelo estimado como:

$\operatorname{Pr}$ (gasto em cultura fora do domicílio) $=f(\log$ da renda per capita; log do gasto em bens complementares; idade; idade ao quadrado; educação do chefe; educação artística; sexo do chefe; cor; ter filhos com idade inferior a 10 anos, dummy de ano e dummies de região)

\section{Descrição das Variáveis}

Tendo por referência o modelo formal apresentado, e tentando compatibilizá-lo com as informações disponíveis nas bases de dados utilizadas, selecionou-se o seguinte conjunto de variáveis a serem incluídas no modelo. A variável gcult-externo é a variável dependente e representa uma variável binária igual a 1 caso o domicílio declare algum gasto com produtos artístico-culturais consumidos fora do domicílio, e igual a 0 caso contrário (Quadro 1 ). O conjunto de gastos que compõe o que está sendo denominado consumo cultural fora do domicílio diz respeito aos gastos com cinema, teatro, shows, circo, museu, exposições e espetáculos de dança.

Dentre as variáveis explicativas, utilizam-se como variáveis socioeconômicas a renda domiciliar per capita e o gasto em bens complementares. ${ }^{10}$ A primeira variável é equivalente à renda total mensal do domicílio dividida pelo número de moradores e logaritimizada.

${ }^{10} \mathrm{O}$ termo 'bens complementares' deve ser entendido aqui em sentido amplo como bens que, em geral, são consumidos com determinado bem específico. Não está relacionado, portanto, com o seu sentido econômico estrito, avaliado pela elasticidade-preço da demanda cruzada. 
A ideia de incluir a variável relativa à renda domiciliar é captar o efeito da renda enquanto restrição ao consumo, por isso é esperado um efeito positivo direto, ou seja, acredita-se que, quanto maior a renda per capita, maior a probabilidade de se despender em produtos culturais.

Quadro 1 - Variáveis incluídas na estimação do modelo Probit

\begin{tabular}{|c|c|}
\hline gcult-externo & $\begin{array}{l}1 \text { - Gasto positivo em bens culturais fora do domicílio. } \\
0 \text { - Gasto nulo em bens culturais fora do domicílio. }\end{array}$ \\
\hline Lnrendapc & Logaritmo da renda domiciliar per capita \\
\hline Lncomp & $\begin{array}{l}\text { Logaritmo do gasto domiciliar em bens complementares (artigos } \\
\text { de áudio, vídeo e leitura, aparelhos e serviços). }\end{array}$ \\
\hline educação artística & $\begin{array}{l}1 \text { - Gasto positivo: cursos e instrumentos musicais. } \\
0 \text { - Gasto nulo: cursos e instrumentos musicais. }\end{array}$ \\
\hline Idade & Idade do chefe do domicílio \\
\hline idade2 & Idade elevada ao quadrado \\
\hline Estudo & Escolaridade do chefe do domicílio (anos de estudo). \\
\hline Sexo & Sexo do chefe do domicílio \\
\hline branca / preta & Dummies para cor do chefe do domicílio (cor de referência: parda) \\
\hline filhos até 10 anos & Número de filhos até 10 anos de idade. \\
\hline $\begin{array}{l}\text { Belém / Fortaleza / Recife/ Belo Horizonte / Rio de } \\
\text { Janeiro / Salvador / Curitiba / Porto Alegre }\end{array}$ & $\begin{array}{l}\text { Dummies para cada região metropolitana da POF. (Região de } \\
\text { referência: São Paulo) }\end{array}$ \\
\hline Ano & $1-2009 ; 0-2003$ \\
\hline
\end{tabular}

A segunda representa o logaritmo da soma dos gastos em bens considerados complementares. Trata-se de produtos da indústria cultural tais como artigos de áudio, vídeo e leitura, além dos aparelhos eletroeletrônicos de suporte, tais como TV, DVD, computador, etc., e serviços relacionados, como tarifas de TV a cabo e internet, uso de internet em Lan Houses, etc. Além das variáveis econômicas, o consumo de produtos culturais também está relacionado às características adscritas do chefe do domicílio e a sua escolaridade. Recorre-se às informações do chefe, porque não há na $\mathrm{POF}$ como atribuir gastos a cada um dos componentes do domicílio. Como as características do chefe refletem a estrutura domiciliar e o comportamento familiar, tal restrição não deve criar viés na análise.

A variável sexo é uma variável dicotômica para a qual é atribuída a distinção mulher (0) e homem (1). Outros trabalhos mencionam uma maior propensão das mulheres como consumidoras de bens cul- 
turais. Já as variáveis referentes à cor - branca, preta e parda - são dummies, sendo a cor parda a cor de referência. Em relação à cor é esperada uma maior probabilidade de consumo de produtos culturais para domicílios com chefes brancos, em parte devido à correlação entre raça e classe social.

A variável idade, calculada em anos, também é analisada. É esperado um efeito positivo, uma vez que o consumo passado influencia positivamente o consumo atual. Há, porém, o efeito negativo causado pelo custo de oportunidade, que provavelmente aumenta ao longo do tempo. Este efeito justifica a inclusão de uma variável referente à idade ao quadrado - idade2. Em relação à educação, utilizam-se os anos de estudo. O efeito esperado da variável relacionada à educação é positivo, uma vez que a educação aumenta a chance de contato com bens culturais desde a infância e expande o capital humano, ampliando a capacidade de assimilação.

Quanto às variáveis geográficas criam-se dummies que recebem valor 1 quando os dados dizem respeito a cada uma das seguintes regiões metropolitanas - Belém, Fortaleza, Recife, Salvador, Belo Horizonte, Rio de Janeiro, São Paulo (região de referência), Curitiba e Porto Alegre. É incluída ainda uma variável referente ao número de filhos menores de 10 anos. Espera-se que famílias com maior número de crianças pequenas tenham mais dificuldade em consumir produtos culturais fora do domicílio, seja pela necessidade de cuidado com as crianças, que restringe o tempo disponível, seja por um efeito substituição entre gastos ligados ao lazer e gastos referentes à educação dos filhos.

Para controlar o fato de trabalhar com um conjunto de dados referentes a dois períodos distintos, inclui-se uma variável dicotômica para ano, que assume valor 1 para 2008-2009 e 0 para 2002-2003, conforme os períodos de referência das pesquisas. Espera-se que o efeito dessa variável seja positivo, uma vez que, durante esse período, houve ganho em termos de escolaridade e renda per capita das famílias brasileiras.

Por fim, inclui-se uma proxy para testar o efeito "vício positivo" relatado no modelo de Stigler e Becker (1977). Trata-se de uma dummy referente aos domicílios que possuem gasto positivo com cursos relacionados a atividades artísticas - curso de dança, de pintura, 
de teatro, etc. - e com instrumentos musicais. Acredita-se que este tipo de gasto está intimamente relacionado ao hábito de consumir produtos culturais fora do domicílio, por estimular o contato com a arte e a cultura. Apesar de não considerar uma defasagem temporal entre os dois tipos de consumo, acredita-se que este tipo de gasto seja, em geral, realizado de forma contínua, o que implica supor que também tenha sido realizado no passado.

\section{Tratamento dos Dados}

A amostra da POF 2002-2003 é composta por 48.470 domicílios, enquanto a POF 2008-2009 totaliza 55.970 domicílios, o que somado representa uma amostra de 104.440 domicílios.

Destes, limitou-se a base àqueles domicílios cuja pessoa de referência possui data de nascimento entre 1931 e 1985, o que representa, para 2003, os indivíduos com idade entre 18 e 70 anos. Foram excluídos da amostra também aqueles domicílios que continham dados faltantes em relação à cor e à escolaridade do chefe e os domicílios com gasto total nulo, tratados como missing. Desconsideraram-se ainda os domicílios com chefes que declaram cor da pele indígena e amarela (uma vez que representam conjuntamente menos de 1\% da amostra total). Assim, os dados referentes ao Brasil correspondem a uma amostra de 94.884 domicílios.

O restante da análise, tanto descritiva quanto econométrica, restringiu-se ao conjunto de informações referentes às nove regiões metropolitanas da POF, o que representa uma amostra de 12.165 observações, sendo 5.375 referentes ao período 2002-2003 e 6.790 referentes ao período 2008-2009.

\section{Resultados}

\section{Análise Descritiva}

O consumo de bens e serviços artístico-culturais é restrito a uma pequena parcela dos domicílios brasileiros. Somente $27 \%$ declaram algum gasto com este tipo de bem na POF 2002-2003, e este percen- 
tual cresce muito pouco desde então, chegando a 27,13\% em 20082009 (TAB. 1). Considerando somente esta parcela dos domicílios, o montante gasto com produtos culturais passa de $0,96 \%$ para $1,16 \%$ do gasto domiciliar total médio em consumo entre os dois períodos.

Ao considerar somente as regióes metropolitanas, o percentual de domicílios consumidores é maior. Este resultado ressalta a importância da localização como condicionante da oferta, principalmente a vantagem dos grandes centros urbanos (que também são as áreas de maior concentração de renda) e valida o indicado na literatura internacional (Ateca-Amestoy, 2008; Ringstad e Loyland, 2006) e nacional (Earp e Sroulevich, 2009). Porém, este percentual de domicílios cai entre os dois períodos, passando de $39 \%$ para $32,5 \%$, o que vai contra o esperado dado o crescimento da economia brasileira. Uma das possíveis explicações para essa queda pode estar relacionada à crise econômica de 2008, que agiu como fator de desestímulo ao consumo durante certo período correspondente ao período da pesquisa. A redução no número de domicílios, porém, foi compensada por um aumento na participação sobre o gasto total.

Ao analisar cada região metropolitana, é interessante notar que há uma mudança no ranking em relação ao percentual de domicílios consumidores, sendo que os dois primeiros lugares, Porto Alegre e Salvador em 2002-2003, passam a ser Belo Horizonte e Recife em 2008-2009.

Quando se limita a análise somente aos produtos culturais relacionados a atividades fora do domicílio, têm-se uma participação de apenas $10 \%$ dos domicílios brasileiros, nos dois períodos, enquanto para as regiões metropolitanas essa participação cai de 18\% para $15 \%$ entre os períodos. No ranking das regiões metropolitanas, São Paulo é a região que possui o maior percentual de domicílios consumidores nos dois períodos, seguido por Porto Alegre em 2002-2003 e por Belo Horizonte em 2008-2009. Belo Horizonte e Belém são as únicas regiões que registram aumento no percentual de domicílios entre os dois períodos. Em relação à participação sobre o gasto total há um crescimento significativo para todas as regiões.

Com relação à composição deste gasto em bens culturais externos, é importante ressaltar que, de todas as práticas consideradas (museu, teatro, circo, shows, exposições, cinema e dança), somente gastos 
com shows, cinema e teatro estão presentes em um percentual de domicílios superior a $1 \%$ nos dois períodos. Estes percentuais são de $15,27 \%$ para o teatro, $7,56 \%$ para shows e $86,9 \%$ para o cinema em 2008-2009. Apesar de muito restrito, porém, o percentual de domicílios que registraram gastos com museus e exposições aumentou $240 \%$ e $417 \%$, respectivamente. Este crescimento no caso do teatro e dos shows foi de cerca de $16 \%$ entre os períodos, enquanto o percentual de domicílios que registraram gastos com cinema caiu $5 \%$.

Já em relação aos bens complementares, há crescimento do número de domicílios que declaram gasto positivo com este tipo de bem, assim como na participação sobre o gasto total. Para o Brasil, a alta foi de $57,5 \%$ dos domicílios pra $67,7 \%$. Já as regiões metropolitanas registram um crescimento bem menor, de $69,8 \%$ para $70,8 \%$. Este resultado revela que a democratização dos gastos em cultura no Brasil tem sido realizada principalmente via produtos culturais domiciliares associados aos gastos com aparelhos de suporte como televisão, aparelho de DVD, celulares, computadores, etc. A expansão deste tipo de gasto pode ser explicada, dentre outros motivos, pelo aumento do acesso ao crédito. Um menor crescimento no caso das regiões metropolitanas indica que este gasto se ampliou principalmente no interior do país - São Paulo, Rio de Janeiro e Curitiba registram queda. É interessante notar ainda como Belém sobe da oitava para a primeira posição no ranking referente ao percentual de domicílios consumidores. Por outro lado, é preciso destacar que, ainda em 2008-2009, uma parcela de mais de 30\% dos domicílios brasileiros não declara nenhum gasto com este tipo de bem.

Finalmente, no que diz respeito aos gastos com cursos ligados à arte e com a compra de instrumentos musicais, considerados como gastos em educação artística, o percentual de domicílios que declaram algum gasto é substancialmente baixo, não atingindo $5 \%$ nem mesmo no caso das regiões metropolitanas. Entre os dois períodos há uma pequena elevação deste percentual, com exceção de Belo Horizonte, Salvador e Porto Alegre, que registram queda. Com relação à participação sobre o gasto total, este sobe no caso do Brasil, mas cai para as regiões metropolitanas, principalmente em São Paulo, Rio de Janeiro e Curitiba. 


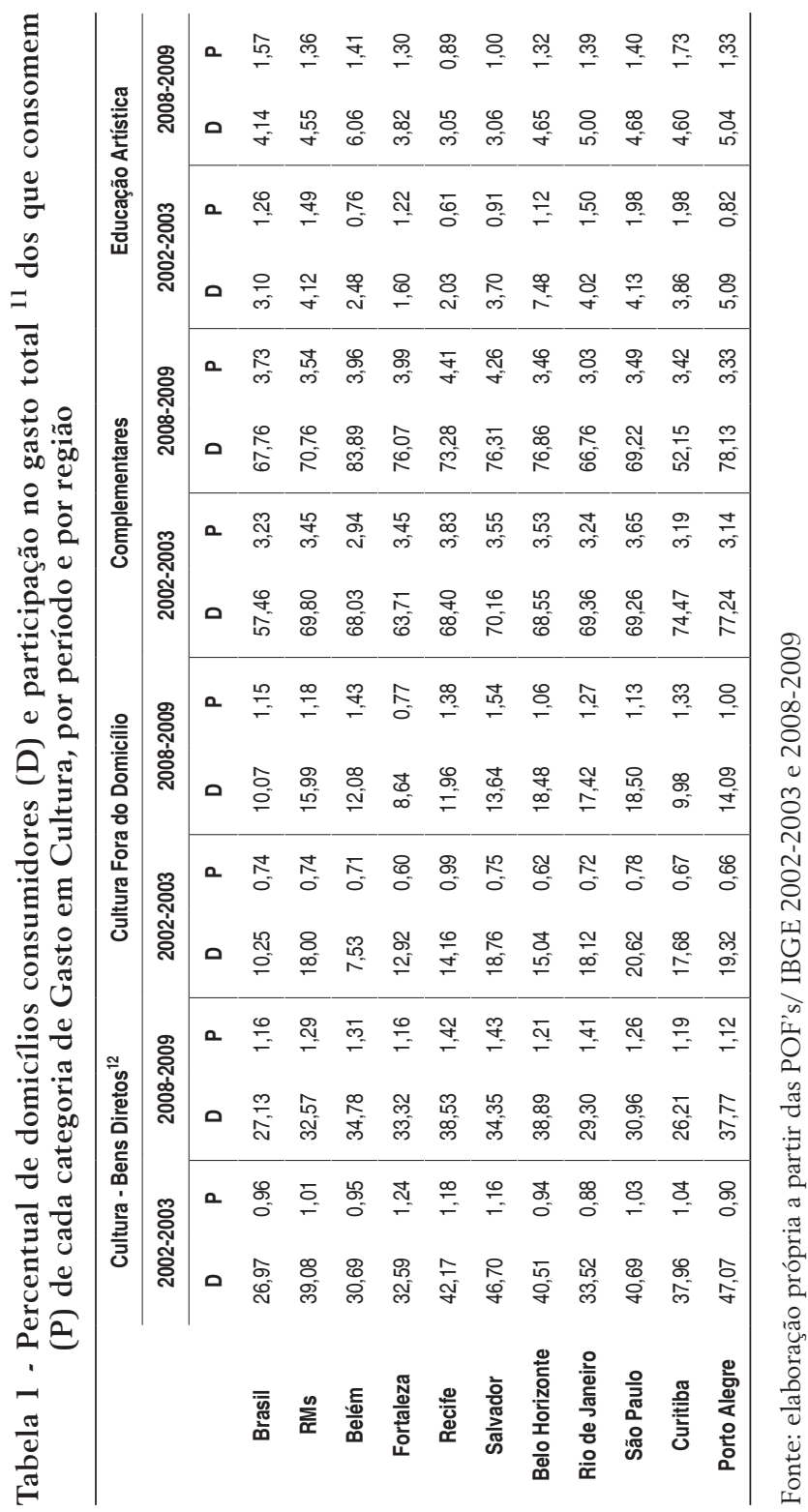

${ }^{11}$ A variável referente ao gasto total representa a soma de todos os gastos com consumo do domicílio, excetuando-se gastos com aluguel, e acrescentando-se a estimativa da soma do valor dos bens inventariados referentes a aparelhos eletroeletrônicos considerados entre os bens complementares. Este valor dos bens inventariados também é incluído na construção da variável referente ao gasto com bens complementares.

${ }^{12}$ A definição de bens culturais diretos se baseia em Diniz (2009), e dizem respeito às obras de arte propriamente ditas (artes plásticas ou visuais), espetáculos ao vivo (artes performáticas e mercadorias advindas das indústrias culturais como a do cinema, livro e disco. 
A Tabela 2 apresenta o percentual de domicílios consumidores de produtos culturais fora do domicílio, diferenciando estes percentuais pelas características referentes à pessoa de referência: sexo, cor, escolaridade, número de filhos com menos de 10 anos de idade e também por quartos de renda domiciliar. A tabela inclui ainda a representatividade de cada categoria das variáveis apresentadas também para os dois períodos. Em relação ao sexo da pessoa de referência, em ambos os períodos, a proporção de mulheres chefes de domicílios representa cerca de um terço da amostra. Quando se trata do percentual de domicílios que declaram gasto com produtos culturais fora do domicílio, este percentual é mais elevado para os domicílios chefiados por mulher em 2002-03, ocorrendo o contrário em 200809, o que não deixa claro se é possível dizer que há uma tendência às mulheres serem maiores consumidoras deste tipo de produto. Esta hipótese se baseia no uso de práticas culturais pelas mulheres como forma de socialização, o que para os homens estaria mais associado a práticas relacionadas ao esporte.

No que diz respeito à cor declarada pelo chefe, é possível notar que este é um fator que diferencia fortemente o percentual de domicílios consumidores, sendo a participação dos domicílios, cujo chefe é branco, duas vezes a participação dos domicílios cujo chefe é negro, em 2002-2003. Esta diferença diminui pouco em 2008-2009. Quando se trata dos domicílios que declaram gasto positivo com produtos culturais externos, são os chefes entre 40 e 60 anos que possuem os maiores percentuais, sendo que em 2002-2003 este percentual era maior para a faixa entre 41 e 50 anos; já em 2008-09, para a faixa entre 51 e 60 . Somente a faixa etária mais jovem, de 18 a 25 anos, registra aumento do percentual de domicílios consumidores, o que possui a característica positiva de ser a faixa etária associada a chefes de classes sociais mais baixas.

Já em relação à escolaridade, a amostra da POF é relativamente bem distribuída em relação aos anos de estudo, notando-se que há um ligeiro deslocamento da amostra para faixas de maior escolaridade de 2002-2003 pra 2008-2009. Os saltos em relação ao percentual de domicílios que gastam com produtos culturais externos são bem marcados entre indivíduos que possuem somente ensino fundamental e que possuem ensino médio, e ainda entre aqueles que possuem ensino médio em relação aos que possuem níveis superiores de educação. De 2002-2003 para 2008-2009 há aumento da participação 
de domicílios com chefes de menor escolaridade, enquanto os domicílios com chefes mais escolarizados registram queda. Este resultado parece indicar que fatores associados à expansão da educação possuem, pelo menos a curto prazo, menor peso na democratização do acesso a bens culturais que outros fatores, como o crescimento da renda.

Apesar disso, a escolaridade é fundamental para identificar aqueles que mais participam, sendo que a diferença quando a escolaridade é superior a 11 anos para aqueles chefes não escolarizados é de, no mínimo, três vezes mais participação, sendo que esta diferença reduziu-se entre os dois períodos.

Tabela 2 - Percentual de domicílios consumidores de produtos culturais fora do domicílio, por características sociodemográficas do chefe do domicílio e quartos de renda domiciliar, para 2002-03 e 2008-09

\begin{tabular}{|c|c|c|c|c|c|}
\hline & & \multicolumn{2}{|c|}{$2002-2003$} & \multicolumn{2}{|r|}{$2008-2009$} \\
\hline & & $\begin{array}{l}\text { Domicílios da } \\
\text { POF (\%) }\end{array}$ & $\begin{array}{l}\text { Domicílios consumidores } \\
\qquad(\%)\end{array}$ & $\begin{array}{l}\text { Domicílios da } \\
\text { POF (\%) }\end{array}$ & $\begin{array}{l}\text { Domicílios consumidores } \\
\qquad(\%)\end{array}$ \\
\hline \multirow{2}{*}{ SEXO } & Mulher & 30,41 & 19,62 & 33,01 & 15,46 \\
\hline & Homem & 69,59 & 17,29 & 66,99 & 16,26 \\
\hline \multirow{3}{*}{ COR } & Branca & 55,03 & 23,99 & 51,17 & 20,18 \\
\hline & Preta & 10,97 & 10,64 & 11,88 & 12,76 \\
\hline & Parda & 34 & 10,66 & 36,95 & 11,24 \\
\hline \multirow{6}{*}{ FAIXA ETÁRIA } & 18 a 25 & 6,76 & 12,74 & 3,31 & 15,14 \\
\hline & 26 a 30 & 10,81 & 11,69 & 9,52 & 13,52 \\
\hline & 31 a 40 & 28,37 & 15,92 & 23,06 & 15,29 \\
\hline & 41 a 50 & 27,86 & 22,30 & 25,20 & 17,91 \\
\hline & 51 a 60 & 16,3 & 22,77 & 19,77 & 19,18 \\
\hline & mais de 60 & 9,89 & 14,46 & 19,14 & 12,40 \\
\hline \multirow{7}{*}{$\begin{array}{l}\text { ANOS DE } \\
\text { ESTUDO }\end{array}$} & 0 & 5,53 & 7,40 & 5,61 & 11,12 \\
\hline & 1 a 3 & 12,08 & 7,36 & 9,99 & 6,53 \\
\hline & 4 a 7 & 30 & 7,99 & 23,60 & 8,04 \\
\hline & 8 & 11,74 & 8,75 & 7,15 & 10,01 \\
\hline & 9 a 10 & 6,07 & 15,27 & 7,26 & 9,81 \\
\hline & 11 & 18,25 & 22,78 & 23,39 & 16,57 \\
\hline & mais de 11 & 16,32 & 50,18 & 23,00 & 32,69 \\
\hline \multirow{5}{*}{$\begin{array}{c}\mathrm{N}^{0} \text { FILHOS ATÉ } \\
10 \text { ANOS }\end{array}$} & 0 & 61,27 & 22,66 & 69,75 & 17,88 \\
\hline & 1 & 23,32 & 12,14 & 19,77 & 13,14 \\
\hline & 2 & 11,19 & 9,79 & 7,66 & 10,71 \\
\hline & 3 & 3,25 & 4,23 & 2,17 & 2,68 \\
\hline & 4 ou mais & 0,97 & 5,29 & 0,65 & 7,45 \\
\hline \multirow{4}{*}{$\begin{array}{l}\text { QUARTOS DE } \\
\text { RENDA }\end{array}$} & 1 & 24,33 & 1,53 & 14,64 & 1,98 \\
\hline & 2 & 24,89 & 3,90 & 21,08 & 4,20 \\
\hline & 3 & 23,63 & 8,53 & 27,73 & 7,43 \\
\hline & 4 & 27,15 & 25,40 & 36,55 & 18,71 \\
\hline TOTAL & & 100 & 10,25 & 100,00 & 10,07 \\
\hline
\end{tabular}


Outra característica que parece fundamental para diferenciar o grupo dos que consomem produtos culturais externos daqueles que não consomem é o número de filhos menores de 10 anos. Quase 70\% dos domicílios da POF não possuem filhos nesta faixa etária, enquanto número inferior a $5 \%$ dos domicílios possuem mais de três filhos pequenos.

Quando comparamos com relação ao gasto em práticas culturais externas, em torno de $17 \%$ dos domicílios sem filhos pequenos consomem este tipo de bem em 2008-2009, enquanto para domicílios com três filhos pequenos este percentual cai para apenas $2,7 \%$. Na comparação entre os dois períodos, porém, enquanto os domicílios com filhos aumentam a participação, os domicílios sem filhos diminuem a participação no consumo de produtos externos.

A renda parece ser o principal fator de determinação com base na análise descritiva. A participação das famílias dos dois primeiros quartis de renda é muito pequena, e, mesmo crescendo entre os dois períodos, não ultrapassa $5 \%$. O maior salto, porém, dá-se do terceiro para o último quartil, passando de $7,4 \%$ para $18,7 \%$ em 2008-2009. Ao contrário do que acontece com os primeiros quartis, tanto o terceiro quanto o quarto registram queda no percentual de domicílios de um período para o outro.

Fatores Associados à Frequência: Resultados da Estimação do Probit

Os resultados do modelo Probit expressos na Tabela 3 reportam os efeitos marginais, o que permite que os valores dos coeficientes sejam interpretados. Neste sentido é possível afirmar, por exemplo, que um aumento de $1 \%$ na renda per capita corresponderia a um aumento de $4,3 \%$ na probabilidade de gastar com produtos culturais fora do domicílio, sendo este resultado significativo a $1 \%$.

Este resultado vai ao encontro do esperado, e é muito semelhante ao encontrado por Machado, Menezes e Diniz (2010) com relação ao cinema. O resultado em relação ao logaritmo dos gastos complementares, por exemplo, é positivo e significativo a $1 \%$, o que nos permite inferir que práticas culturais externas e domiciliares se alimentam mutuamente, assim como encontrado no estudo de Botelho e Fiore (2005). Este resultado também confirma o de Ateca-Amestoy 
(2008), que demonstra que literatura e filmes são complementares aos espetáculos teatrais, e não substitutos. Ao analisar as características do chefe do domicílio, os resultados revelam que, em relação à idade, há ganhos decrescentes na probabilidade de se consumir produtos culturais fora do domicílio à medida que o indivíduo se torna mais velho.

Mais uma vez o resultado confirma as expectativas (Ateca-Amestoy, 2008; Ringstad e Loyland, 2006; Machado e Menezes e Diniz, 2010), uma vez que, se por um lado o aumento da idade se relaciona a ganhos de introspecção e redução do preço sombra, por outro lado também pode estar relacionado ao crescimento do custo de oportunidade, em virtude do tempo despendido com atividades laborais e insegurança quanto à violência urbana.

A variável relacionada à escolaridade também se mostra positiva e significativa como esperado, bem como a variável que diz respeito à educação artística. Esta variável foi utilizada como uma proxy e serve para testar o efeito "vício positivo", mostrando-se estar de acordo com a hipótese de que a educação artística representa ganhos, em termos de capital cultural, que refletem na probabilidade de se consumir bens culturais, uma vez que reduz o preço-sombra. 
Tabela 3 - Resultados da estimação do PROBIT - Reportando Efeitos Marginais

\begin{tabular}{|c|c|}
\hline Gcult-externo & Coeficientes \\
\hline Ln(rendapc) & $\begin{array}{c}0,0433^{\star \star \star} \\
(0,0039253) \\
0,0193^{\star \star \star}\end{array}$ \\
\hline Ln(complementares) & $(0,0011567)$ \\
\hline Educação artística & $0,0744^{\star \star \star}$ \\
\hline Idade & $\begin{array}{c}0,0089^{\star \star *} \\
(0,0016418)\end{array}$ \\
\hline Idade2 & $\begin{array}{c}-0,0001^{\star \star *} \\
(0,0000172)\end{array}$ \\
\hline Anos de Estudo & $\begin{array}{c}0,0081^{\star \star \star} \\
(0,0008226)\end{array}$ \\
\hline Sexo & $\begin{array}{c}-0,0227^{\star \star *} \\
(0,0065453)\end{array}$ \\
\hline Branca & $\begin{array}{c}0,0286^{\star \star *} \\
(0,0070377)\end{array}$ \\
\hline Preta & $\begin{array}{c}0,0010 \\
(0,0107333)\end{array}$ \\
\hline Filhos até 10 anos & $\begin{array}{c}-0,0282^{\star \star *} \\
(0,0048977)\end{array}$ \\
\hline Belém & $\begin{array}{c}-0,0472^{\star \star \star} \\
(0,0102602)\end{array}$ \\
\hline Fortaleza & $\begin{array}{c}-0,0216^{\star *} \\
(0,0109297)\end{array}$ \\
\hline Recife & $\begin{array}{c}-0,0180^{\star *} \\
(0,0104113)\end{array}$ \\
\hline Belo Horizonte & $\begin{array}{c}-0,0115 \\
(0,009694) \\
-0,0156\end{array}$ \\
\hline Rio de Janeiro & $(0,0094283)$ \\
\hline Salvador & $\begin{array}{c}-0,0015 \\
(0,0125096)\end{array}$ \\
\hline Curitiba & $\begin{array}{c}-0,0343^{\star \star \star} \\
(0,0100797) \\
-0,0294^{\star \star \star}\end{array}$ \\
\hline Porto Alegre & $\begin{array}{c}(0,0094292) \\
-0,0205^{\star \star \star}\end{array}$ \\
\hline & $(0,0060635)$ \\
\hline Observações & 12.165 \\
\hline Obs. P & 0,1546239 \\
\hline Pred. P & 0,1110381 \\
\hline Log pseudolikelihood & $-4320,639$ \\
\hline Wald chi2(19) & $1.418,40$ \\
\hline Prob $>$ chi2 & 0.0000 \\
\hline Pseudo R2 & 0,1753 \\
\hline
\end{tabular}

Obs.: Desvio-padrão robusto entre parênteses

${ }^{*}$ significativo a $10 \% ;{ }^{* *}$ significativo a $5 \%{ }^{* * *}$ significativo a $1 \%$. 
Em relação ao sexo, o sinal negativo e significativo indica que há uma maior probabilidade das mulheres despenderem com bens culturais externos que os homens, resultado também encontrado por AtecaAmestoy (2008) em relação ao teatro e por Diniz e Machado (2011) quando considera somente os domicílios que mais gastam com cultura. Já no que diz respeito à cor, tendo por referência a cor parda, somente a cor branca mostrou-se significativamente positiva.

Finalmente a variável referente ao número de filhos menores de 10 anos, que busca captar a importância da disponibilidade de tempo para a prática de atividades culturais que envolvem saídas do domicílio, mostrou-se negativa e significativa, sugerindo a rivalidade entre tempo alocado no cuidado com crianças e em atividades culturais. $\mathrm{O}$ fato desse efeito negativo estar associado especificamente a práticas externas pode ser constatado quando confronta-se este resultado com o encontrado por Ringstad e Loyland (2006) ao investigar a demanda por livros, uma vez que neste caso encontram um resultado significativo, porém positivo, para o fato de se ter filhos menores de sete anos. O resultado também corrobora o encontrado por Machado, Menezes e Diniz (2010). Em relação aos coeficientes das regiões metropolitanas, tendo São Paulo como região de referência, todos apresentam sinal negativo, porém não são significativos os coeficientes das regiões metropolitanas de Salvador, Rio de Janeiro e Belo Horizonte. Além disso, os coeficientes de Fortaleza e Recife não são significativos a $1 \%$. Este resultado implica dizer que, excetuando-se Belo Horizonte, Rio de Janeiro e Salvador, estar localizado nas demais regiões metropolitanas reduz a probabilidade de se consumir bens culturais externos em relação a São Paulo.

Por fim, resta analisar o coeficiente referente ao controle de ano. Este coeficiente mostrou-se negativo e significativo, o que já era esperado com base na análise descritiva, que registra queda no percentual de domicílios consumidores. Entender os motivos que levam a esta redução, contudo, não é trivial. Como já mencionado, o crescimento econômico do período gera a expectativa de uma diferença positiva, o que pode não ter sido detectado pela POF 2008-2009 devido aos efeitos da crise. Outra possibilidade é o incremento do crédito pessoal que contribui para aumentar o gasto com bens duráveis, dificultando, principalmente para as famílias mais pobres, alocar recursos para frequência em atividades culturais. 


\section{Considerações Finais}

Ainda que a diversidade cultural brasileira seja expressiva e o acesso à cultura bem abrangente, no âmbito das atividades culturais privadas desenvolvidas nos diversos equipamentos como museus, salas de cinema, teatros, entre outros, o acesso é ainda muito limitado. Concentra-se em determinada parcela da população, caracterizada por um perfil demográfico, educacional e econômico, como também pelas condições de oferta dentro do contexto regional em que os indivíduos estão inseridos. De certa forma, o dispêndio em cultura reflete a desigualdade de rendimentos presente no país (Silva et al., 2007).

Para aqueles que despendem com cultura fora do domicílio, prevalece a aquisição de ingressos para cinema, shows e teatros, reforçando um caráter "unívoro" do perfil de consumidores metropolitanos brasileiros no que diz respeito à cultura. Embora presente em todas as faixas de renda, este comportamento "unívoro" predomina entre os mais pobres. Esses consumidores, quando gastam com cultura fora do domicílio, gastam com cinema.

Tal realidade pode se associar ao ambiente elitizado de teatros e museus que acabam por inibir o acesso de indivíduos mais pobres. Nesse contexto, é fundamental a formulação de políticas que incentivem a democratização dos espaços culturais. No período analisado, identifica-se aumento do consumo de bens duráveis como televisão, computadores, que são aqui tratados como complementares ao gasto com cultura dentro do domicílio. Tais dispêndios cresceram não somente em número de domicílios que passam a possuí-los, como também no montante gasto dos que já os tinham. Entretanto, este crescimento ocorreu, especialmente, entre os domicílios que não gastam com atividades culturais externas, os situados na base da distribuição de renda. Ao se considerar, no entanto, que tal tipo de consumo é complementar ao consumo fora do domicílio, espera-se que, no futuro, a prática externa também aumente. Ademais, os achados deste artigo evidenciam que renda e escolaridade são os principais fatores associados ao perfil do consumidor de cultura fora do domicílio. Chama atenção, no entanto, o papel da educação artística na configuração deste perfil, respaldando a hipótese de vício positivo de Stigler e Becker (1977), uma vez que tal formação assegura contato prévio e retroalimentador com o hábito de consumir cultura. 
Ao considerar somente o dispêndio com atividades culturais fora do domicílio, o trabalho avança no sentido de evitar a análise de uma cesta de bens e serviços muito heterogêneos, como trabalhado em outros estudos sobre este tema no Brasil. A restrição ao gasto privado imposta pelas características da organização da base de dados pode se traduzir em uma limitação aos resultados, porque não revela todas as preferências dos indivíduos, haja vista que existem outras formas de consumo cultural fora do domicílio resultantes de estratégias comunitárias ou por meio de financiamento público.

Nesse aspecto, o foco das políticas públicas culturais tem enfatizado a importância da Economia Criativa não somente como um mecanismo de aprimoramento da produção neste setor, mas também como forma de reconversão de espaços e estímulo à democratização do acesso. No livro organizado por Reis e Kageyama (2009) há descrições de experiências bem sucedidas de cidades cuja gestão direcionou ações para tal propósito. O caso emblemático é o de Medellín, na Colômbia, onde a população local teve prioridade, entre outras, de acesso gratuito a museus e espetáculos, além dos jovens residentes serem contemplados com bolsas para formação cultural.

No Brasil, por meio de muitas iniciativas, em especial do Ministério da Cultura, canais de financiamento estão sendo criados para construção de "fábricas criativas" e, recentemente, foi editada política para credenciar cidades em seu aspecto criativo. Tais mecanismos abrem perspectivas para a produção artístico-cultural como também para o consumo desta, tornando a cidade um espaço efervescente, como sugerido por Florida (2004).

\section{Referências}

AGENDA 21 da Cultura. Barcelona: 2004. Disponível em: <http://agenda21culture.net/index. php?option $=$ com_content $\&$ view $=$ article $\&$ id $=44 \&$ Itemid $=58 \&$ lang=pt $>$ Acesso em: 28 de maio de 2011.

ATECA-AMESTOY, V. Determining heterogeneous behavior for theater attendance.

Journal of Cultural Economics, Akron, v. 32, n. 2, p. 127-151, Jun. 2008.

BECKER, G.S. A theory of the allocation of time. Economic Journal, 75, 493-517, set. 1965.

BOTELHO, I.; FIORE, M. O uso do tempo livre e as práticas culturais na Região Metropolitana de São Paulo: relatório da primeira etapa da pesquisa. São Paulo: Centro de Estudos da Metrópole, 2005. 125 p. 
BOURDIEU, P. A distinção: crítica social do julgamento. Porto Alegre: Zouk, 2007.

DIMAGGIO, P. Classification in art. American Sociological Review, Aliso Viejo, v. 52,n. 4, p. 440-455, Ago. 1987.

DINIZ, S. C. Análise do consumo de bens e serviços artístico-culturais no Brasil metropolitano. Dissertação (Mestrado em Economia) - Centro de Desenvolvimento e Planejamento Regional, 2009.

DINIZ, S. C.; MACHADO, A. F. Analysis of the Consumption of Artistic-Cultural Goods and Services in Brazil. Journal of Cultural Economics, v. 35, p. 1-18, 2011.

MACHADO, A. F.; MENEZES, T; DINIZ, S. C. Perfil dos consumidores de cinema no Brasil metropolitano, 2009. In: VIII Encontro Nacional da Associação Brasileira de Estudos Regionais e Urbanos, 2010, Juiz de Fora - MG. Anais do VIII ENABER, 2010.

EARP. O espectador eventual: notas sobre a demanda por cinema no Brasil. Políticas Culturais em Revista, v. 01, p. 77-87, 2009.

EARP, Fabio; SROULEVICH, Helena. O comportamento do consumidor de produtos culturais e os combos de entretenimento. In: MELO, Victor A. (Org.). Lazer: aspectos históricos, configurações contemporâneas. São Paulo: Alínea, 2009.

FLORIDA, Richard. The Rise of the Creative Class: And How It's Transforming Work, Leisure, Community and Everyday Life. New York: Basic Books, 2004.

GAPINSKI, J. H. The Economics of Performing Shakespeare. American Economic Review, vol.74, n.3, p. 458-466, Jun. 1984.

GAPINSKI, J. H. The Lively Arts as Substitutes for the Lively Arts. American Economic Review, vol.76, n.2, p. 20-25, May 1986.

HERSCOVICI, Alain. Economia da Cultura e da Comunicação. Vitória: Editora Fundação Ceciliano Abel de Almeida, UFES, 1995.

INSTITUTO BRASILEIRO DE GEOGRAFIA E ESTATÍSTICA - IBGE. Sistema de informações e indicadores Culturais - 2003. Rio de Janeiro: IBGE, 2006.

MARSHALL, A. Principles of economics Londres: MacMillan and Co, 1890 apud REIS, A. C. F. Economia da cultura e desenvolvimento sustentável: o caleidoscópio da cultura. Barueri: Manole, 2007. $354 \mathrm{p}$.

MOORE, T. G. The Demand for Broadway Theatre Tickets. Review of Economics and Statistics, vol.48, n.1, p. 79-87, Feb. 1966.

PETERSON, R. A., SIMKUS, A. How Musical Tastes Mark Occupational Status Groups. In: LAMONT, M. FOURNIER, M. Cultivating Differences: Simbolic Boundaries and the Making of Inequality. Chicago: The University of Chicago Pres, 1992.

REIS, A. C. F. Economia da cultura e desenvolvimento sustentável: o caleidoscópio da cultura. Barueri: Manole, 2007, $354 \mathrm{p}$.

REIS, A.C.F. e KAGEYAMA, P. (Org.) Creative City Perspectives. São Paulo: Garimpo de Soluções e Creative Cities Productions, 2009. Disponível em: http://www.garimpodesolucoes.com.br/ downloads/CCP\%20\%20Final\%201pg.pdf

RINGSTAD, V.; LOYLAND, K. The demand for books estimated by means of consumer survey data. Journal of Cultural Economics, Akron, v. 30, n. 2, p. 141-155, Set. 2006.

SILVA, F. B. da; ARAÚJO, H. E.; SOUZA, A. L.. O consumo cultural das famílias brasileiras. In: SILVEIRA, F. G. et al (Orgs.). Gasto e consumo das famílias brasileiras contemporâneas, v. 2, p. 105-142. Brasília: IPEA, 2007.

STIGLER, G. J.; BECKER, G. S. De gustibus non est disputandum. American Economic Review, Nashville, v. 67, n.2, p. 76-90, Mar. 1977.

TOLILA, P. Cultura e economia: problemas, hipóteses, pistas. São Paulo: Iluminuras/Itaú Cultural, 2007.

Est. Econ., São Paulo, vol. 42, n.4, p. 701-730, out.-dez. 2012 
TRIENEKENS, S. 'Colorful' distinction: the role of ethnicity and ethnic orientation in cultural consumption. Poetics, North-Holland, v. 30, n. 4, p. 281-298, Aug. 2002.

WERCK, K; HEYNDELS, B. Programmatic choices and the demand for theatre: the case of Flemish theatres. Journal of Cultural Economics, vol. 31, p. 25-41, Jan. 2007.

WOOLDRIDGE, J. M. Modelos com variáveis dependentes limitadas e correções da seleção amostral. In: WOOLDRIDGE, J. M. Introdução à econometria: uma abordagem moderna. São Paulo: Thomsom Learning, 2007, p. 517-558.

ZIEBA, M. Full-income and Price Elasticities of Demand for German Public Theatre. Journal of Cultural Economics vol. 33, p. 85-108, Mar. 2009. 